\title{
Percepção de farmacêuticos sobre suas funções técnicos-assistências e técnicos- gerenciais em farmácias comunitárias privadas
}

\author{
Pharmacists' perception of their technical-assistance and managerial-technical functions in private \\ community pharmacies
}

Percepción de los farmacéuticos sobre sus funciones técnico-asistenciales y directivo-técnicas en las farmacias comunitarias privadas

\author{
Divaldo da Silva Moraes Filho \\ ORCID: https://orcid.org/0000-0001-8031-1367 \\ Universidade Federal do Pará, Brasil \\ E-mail: divaldomoraesufpa@gmail.com \\ Lucas Henrique Carvalho Martins \\ ORCID: https://orcid.org/0000-0002-1128-8420 \\ Universidade Federal do Pará, Brasil \\ E-mail: 1lucashcmartins@gmail.com \\ Roberta Neves Costa \\ ORCID: https://orcid.org/0000-0001-7621-8127 \\ Conselho Regional de Farmácia do Pará, Brasil \\ E-mail: assessoriafarmaceutica@crfpa.org.br \\ Luana Melo Diogo de Queiroz \\ ORCID: https://orcid.org/0000-0001-5036-5639 \\ Universidade Federal do Pará, Brasil \\ E-mail: luanaqueiroz@ufpa.br \\ Márcia Maria Barros dos Passos \\ ORCID: https://orcid.org/0000-0002-0416-6273 \\ Universidade Federal do Rio de Janeiro, Brasil \\ E-mail:marciabpassos@pharma.ufrj.br \\ Orenzio Soler \\ ORCID: https://orcid.org/0000-0003-2246-0019 \\ Universidade Federal do Pará, Brasil \\ E-mail: orenziosoler@gmail.com
}

\begin{abstract}
Resumo
Objetivo: Identificar as atribuições e/ou funções de farmacêuticos como técnicos-gerenciais e como técnicosassistenciais em farmácias comunitárias privadas. Método: Pesquisa exploratória, prospectiva, analítica e descritiva, realizada entre outubro e dezembro de 2020, utilizando-se de entrevistas estruturadas via Survey Monkey ${ }^{\circledR}$, aplicadas a farmacêuticos que trabalham em farmácias comunitárias privadas no estado do Pará. Resultados: Trata-se de uma representação social sobre a percepção de $59(100,0 \%)$ farmacêuticos respondentes. $32(54,2 \%)$ eram farmacêuticos técnico-assistenciais e 27 (45,8\%) eram farmacêuticos técnico-gerenciais. Identificou-se as atribuições e/ou funções dos farmacêuticos como técnico-gerenciais e como técnicos-assistenciais em farmácias comunitárias privadas. Conclusão: Observou-se que não há harmonização das atribuições e funções dos farmacêuticos como técnico-gerenciais e como técnicos-assistenciais. Infere-se haver conflitos quanto à compreensão do papel dos farmacêuticos como técnicosgerenciais (gestão) e como técnicos-assistenciais (cuidado farmacêutico).

Palavras-chave: Mercado farmacêutico; Farmácia comunitária; Gestão farmacêutica; Serviços farmacêuticos; Cuidado farmacêutico.
\end{abstract}

\begin{abstract}
Objective: To identify the duties and/or functions of pharmacists as managerial technicians and as assistance technicians in private community pharmacies. Method: Exploratory, prospective, analytical, and descriptive research, carried out between October and December 2020, using structured interviews via Survey Monkey®, applied to pharmacists working in private community pharmacies in the state of Pará. Results: This is a social representation on the perception of $59(100.0 \%)$ pharmacists' respondents. 32 (54.2\%) were technical-assistance pharmacists and $27(45.8 \%)$ were technical-management pharmacists. The attributions and/or functions of pharmacists were identified as managerial technicians and as assistance technicians in private community pharmacies. Conclusion: It was observed that there is no harmonization of the duties and functions of pharmacists as managerial technicians and as assistance technicians. It
\end{abstract}


is inferred that there are conflicts regarding the understanding of the role of pharmacists as managerial technicians (management) and as assistance technicians (pharmaceutical care).

Keywords: Pharmaceutical market; Community pharmacy; Pharmaceutical management; Pharmaceutical services; Pharmaceutical care.

\section{Resumen}

Objetivo: Identificar los deberes y/o funciones de los farmacéuticos como técnicos directivos y como técnicos asistenciales en farmacias privadas comunitarias. Método: Investigación exploratoria, prospectiva, analítica y descriptiva, realizada entre octubre y diciembre de 2020, utilizando entrevistas estructuradas a través de Survey Monkey ${ }^{\circledR}$, aplicadas a farmacéuticos que trabajan en farmacias comunitarias privadas en el estado de Pará. Resultados: Se trata de una representación social sobre la percepción de 59 (100,0\%) farmacéuticos encuestados. 32 (54,2\%) eran farmacéuticos de asistencia técnica y $27(45,8 \%)$ farmacéuticos de gestión técnica. Se identificaron las atribuciones y/o funciones de los farmacéuticos como técnicos directivos y como técnicos asistenciales en farmacias privadas comunitarias. Conclusión: Se observó que no hay armonización de los deberes y funciones de los farmacéuticos como técnicos de gestión y como técnicos de asistencia. Se infiere que existen conflictos en cuanto a la comprensión del papel del farmacéutico como técnico gerencial (gerencia) y como técnico asistencial (atención farmacéutica).

Palabras clave: Mercado farmacéutico; Farmacia de la comunidad; Gestión farmacéutica; Servicios farmacéuticos; Cuidado farmacéutico.

\section{Introdução}

No Brasil, o artigo n 196 da Constituição Federal, de 5 de outubro de 1988, diz que “[...] a saúde é direito de todos e dever do Estado, garantido mediante políticas sociais e econômicas que visem à redução do risco de doença e de outros agravos e ao acesso universal e igualitário às ações e serviços para a promoção, proteção e recuperação". Saúde é um direito básico no exercício da cidadania do ser humano, e faz parte do conjunto de direitos sociais. Inspirado no valor da igualdade entre as pessoas, o direito à saúde é de extrema relevância para a sociedade, pois diz respeito à qualidade de vida. A assistência farmacêutica se insere neste contexto; em especial, devido a expansão das atividades clínicas do farmacêutico como resposta ao fenômeno da transição demográfica e epidemiológica observado na sociedade.

O Sistema Único de Saúde (SUS) é um dos maiores sistemas públicos de saúde do mundo. Em 2019, o Brasil contava com 114.352 farmácias comunitárias (76,8\% privadas), que representam o primeiro ponto de acesso à saúde no Brasil devido à sua ampla distribuição. Infelizmente, do ponto de vista do governo, a principal atividade esperada das farmácias comunitárias privadas e públicas está relacionada à dispensação de medicamentos e outros produtos de saúde. As farmácias públicas comunitárias podem fazer parte de um centro de saúde ou estar num local separado, por vezes sem a presença de um farmacêutico. Os farmacêuticos que trabalham nesses locais (isolados) não têm acesso aos prontuários dos pacientes, tendo dificuldade em acessar outros membros da equipe multiprofissional. Farmacêuticos que trabalham em farmácias públicas localizadas em centros de saúde podem ter acesso aos prontuários dos pacientes, mas as atividades da farmácia estão frequentemente sob a supervisão de outros profissionais (Melo et al., 2021).

As farmácias privadas estão normalmente abertas 24 horas por dia, 7 dias por semana, com a presença de um farmacêutico durante 8 horas nos dias úteis. As farmácias comunitárias privadas têm uma integração muito limitada com o Sistema Único de Saúde (SUS), sendo os farmacêuticos a terceira maior força de trabalho em saúde no Brasil, com mais de 221.000 cadastrados no Conselho Federal de Farmácia (CFF). O diploma universitário em farmácia é o único requisito para o ingresso na profissão, sem qualquer exame de proficiência para manutenção ou progressão na carreira. A renda anual do farmacêutico brasileiro é classificada como a $2^{\mathrm{a}}$ profissão mais bem paga com uma renda média anual de $€ 5.502,37$ (em 2020); estando na $16^{\circ}$ posição do ranking nacional de salários, com diferenças entre as regiões do Brasil (Melo et al., 2021).

A descrição das atividades clínicas para farmácias pelo CFF aumentou nos últimos anos, porém ainda há um longo caminho para implementá-las efetivamente na prática (Melo et al., 2021). Há cerca de 42.243 farmacêuticos registrados no Brasil.

Dentre o arcabouço legal brasileiro no âmbito de farmácias e drogarias, a Lei no 5.991, de 17 de dezembro de 1973, define ambas e regulamenta as atividades farmacêuticas nesses cenários; ou seja, “[...] drogaria como estabelecimentos de 
dispensação e comércio de drogas, medicamentos, insumos farmacêuticos e correlatos em suas embalagens originais e, farmácia “[...] como um estabelecimento de manipulação de fórmulas magistrais e oficinais, de comércio de drogas, medicamentos, insumos farmacêuticos e correlatos, compreendendo o de dispensação e o de atendimento privativo de unidade hospitalar ou de qualquer outra equivalente de assistência médica".

Por sua vez, a Lei $\mathrm{n}^{\circ} 13.021$, de 8 de agosto de 2014, dispõe sobre o exercício e a fiscalização das atividades farmacêuticas, definindo a assistência farmacêutica como o "[...] conjunto de ações e de serviços que visem a assegurar a assistência terapêutica integral, promoção, proteção e a recuperação da saúde nos estabelecimentos públicos e privados que desempenhem atividades farmacêuticas, tendo o medicamento como insumo essencial e visando ao seu acesso e ao seu uso racional" (Brasil, 2014). Estabelece, ainda, que as farmácias de qualquer natureza requerem, obrigatoriamente para seu funcionamento, a responsabilidade e a assistência técnica de farmacêutico habilitado na forma da lei, de modo que é obrigatório a presença do farmacêutico em todo seu horário de funcionamento. A farmácia é uma unidade de prestação de serviços destinada a prestar assistência farmacêutica, assistência à saúde e orientação sanitária individual e coletiva, na qual se processe a manipulação e/ou dispensação de medicamentos magistrais, oficinais, farmacopeicos ou industrializados, cosméticos, insumos farmacêuticos, produtos farmacêuticos e correlatos. As farmácias são classificadas segundo sua natureza como:

I - Farmácia sem manipulação ou drogaria: estabelecimento de dispensação e comércio de drogas, medicamentos, insumos farmacêuticos e correlatos em suas embalagens originais;

II - Farmácia com manipulação: estabelecimento de manipulação de fórmulas magistrais e oficinais, de comércio de drogas, medicamentos, insumos farmacêuticos e correlatos, compreendendo o de dispensação e o de atendimento privativo de unidade hospitalar ou de qualquer outra equivalente de assistência médica" (Brasil, 2014).

A Resolução do Conselho Federal de Farmácia (CFF) n 577, de 25 de julho de 2013, dispõe sobre a direção técnica ou responsabilidade técnica de empresas ou estabelecimentos que dispensam, comercializam, fornecem e distribuem produtos farmacêuticos, cosméticos e produtos para a saúde. Estabelece, também, requisitos para o desempenho da responsabilidade técnica. Define a responsabilidade técnica como o ato de aplicar conhecimentos técnicos e profissionais, cuja responsabilidade objetiva está sujeita a sanções de natureza cível, penal e administrativa (Brasil, 2013).

Sabe-se que o farmacêutico, profissional da área de saúde, tem sua formação centrada nos fármacos, nos medicamentos e na assistência farmacêutica, e, de forma integrada, com formação em análises clínicas e toxicológicas, em cosméticos e em alimentos, em prol do cuidado à saúde do indivíduo, da família e da comunidade. Outrossim, sua formação deve ser pautada em princípios éticos e científicos, capacitando-o para o trabalho nos diferentes níveis de complexidade do sistema de saúde, por meio de ações de prevenção de doenças, de promoção, proteção e recuperação da saúde, bem como em trabalho de pesquisa e desenvolvimento de serviços e de produtos para a saúde (Brasil, 2017).

Para conhecer o perfil dos farmacêuticos brasileiros, uma publicação do Conselho Federal de Farmácia (CFF), resultante do estudo realizado com 19.896 (100\%) profissionais, demonstrou que 67.5\% são constituídos de mulheres, em uma faixa etária entre 29 e 38 (41.8\%) anos; 50.4\% são casados, $1.9 \%$ são portadores de necessidades especiais, $6.1 \%$ nasceram na Região Norte, $15.8 \%$ Nordeste, $9.8 \%$ Centro-Oeste, $40 \%$ Sudeste, $28 \%$ Sul e $0.3 \%$ oriundos de outros países (Serafin, 2015).

Em adição, $64.1 \%$ dos farmacêuticos se concentram na gestão, executando atividades de controle de estoque e compra de medicamentos. Na área técnica, a maioria, $89.6 \%$, atua na dispensação de medicamentos. No que se refere às atividades clínicas, $27 \%$ afirmaram que prescrevem medicamentos, $14.2 \%$ trabalham em outras atividades. Quanto ao salário, a faixa de $\mathrm{R} \$ 2.001,00$ a $\mathrm{R} \$ 3.000,00$ se destaca para as regiões Sul e Sudeste, sendo que as regiões Norte e Centro-Oeste apresentam os maiores percentuais de profissionais com rendimentos na faixa acima de $\mathrm{R} \$ 5.001,00$ (Serafin, 2015). 
Neste contexto, este artigo apresenta a percepção de farmacêuticos - registrados no Conselho Regional de Farmácia do Pará (CRF-PA) -, sobre suas funções e/ou atribuições categorizadas como técnicos-assistências e técnicos-gerenciais. Em tempo, compreender a visão desses profissionais sobre sua práxis e dos processos de trabalho presentes nas farmácias comunitárias privadas, pode ajudar a identificar o modus operandi dessa prática e melhor ordenar suas atribuições neste ambiente profissional.

\section{Método}

Trata-se de uma investigação exploratória, prospectiva, analítica e descritiva (Turato, 2005; Yin, 2015; Minayo, 2018), realizada entre outubro e dezembro de 2020, visando identificar a percepção dos farmacêuticos registrados no Conselho Regional de Farmácia do Pará (CRF-PA), quanto as suas funções e/ou atribuições técnicos-assistências e técnicos-gerenciais em farmácias comunitárias privada.

O estado do Pará possuía 5.600 farmacêuticos registrados no Conselho Regional de Farmácia do Pará (CRF-PA) no ano de 2020. Destes, 3.171 farmacêuticos trabalham em farmácias comunitárias públicas e privadas; sendo que 901 (28.4\%) trabalhavam na capital Belém, e 4.699 (71.6\%) trabalhavam nos demais 143 municípios.

Selecionou-se, aleatoriamente, 2.800 farmacêuticos como amostra para o estudo, utilizando-se como critérios de inclusão os farmacêuticos regularizados no Conselho Regional de Farmácia do Pará (CRF-PA), que trabalham em farmácias comunitárias privadas e, como critérios de exclusão farmacêuticos que não trabalham em farmácias comunitárias privadas.

Utilizou-se de formulário estruturado para entrevista com os farmacêuticos por meio da ferramenta Survey Monkey® via Internet ${ }^{\circledR}$, sendo identificadas as atribuições do farmacêutico como técnico-gerencial e como técnico-assistencial. Optou-se, em função do número de perguntas, por não caracterizar a amostra quanto a idade, gênero, tempo de formação e pós-graduação. O formulário estruturado foi constituído de 57 perguntas, com opções de múltiplas respostas sobre as atribuições e atividades desenvolvidas nas farmácias comunitárias privadas, fundamentado nos marcos regulatórios vigentes as quais as farmácias comunitárias privadas estão sujeitas. As opções de resposta competiam a responsabilidade do farmacêutico técnico-assistencial, responsabilidade do farmacêutico técnico-gerencial, responsabilidade de ambos os farmacêuticos e responsabilidade do proprietário do estabelecimento.

Compreende-se, aqui, como farmacêutico técnico-gerencial aquele que responde pelos aspectos de gestão (logística) e como farmacêutico técnico-assistencial aquele que responde pelo cuidado farmacêutico (Gomes et al., 2010; Soler et al., 2010; Correr et al., 2011; Ferreira \& Soler, 2021).

Os dados foram plotados em planilha Excel $^{\circledR}$ 2018, analisados utilizando estatística descritiva e os resultados estão apresentados em tabelas, quadros, figuras e síntese narrativa.

A pesquisa foi submetida à Plataforma Brasil (SISNEP) para registro, cumprindo as regras e normas regulamentadas (Brasil, 2012; 2016b), tendo como o CAAE n 35115920.7.0000.0018 e Parecer Consubstanciado $n^{\circ}$ 4.273.588. Esta investigação não implicou em intervenção ou modificação intencionada de variáveis biológicas, fisiológicas, psicológicas ou sociais em seres humanos. Foram minimizadas as possibilidades de constrangimento e desconforto. Em nenhuma circunstância foi perguntado ou evidenciado o nome do farmacêutico, da farmácia comunitária privada ou da rede de farmácias comunitárias privadas na qual o respondente exercia suas funções.

\section{Resultados e discussão}

$59(100,0 \%)$ farmacêuticos responderam ao Survey Monkey®. 32 (54,2\%) se auto-referiram serem farmacêuticos técnico-assistenciais e 27 (45,8\%) farmacêuticos técnico-gerenciais. 15 (25,4\%) farmacêuticos trabalham em tempo integral. 36 $(61,0 \%)$ trabalham em período parcial, exercendo a função técnico-assistencial. $8(13,6 \%)$ não registraram resposta. 
A Lei $\mathrm{n}^{\mathrm{o}}$ 5.991, de 17 de dezembro de 1973, que regulamenta o controle sanitário de medicamentos, autoriza os farmacêuticos a assumirem a responsabilidade técnica por duas farmácias, desde que uma seja comercial e outra hospitalar. A cumulação da responsabilidade técnica está condicionada à demonstração do farmacêutico de que possui meios e compatibilidade de horário de trabalho para prestar assistência aos dois estabelecimentos. Essa demonstração se dá por meio de declaração prestada pelo profissional nos termos das normas editadas pelo órgão representativo da categoria. Desta forma é possível encontrar farmacêuticos trabalhando meio expediente nestes estabelecimentos, sendo necessário mais de um farmacêutico para o cumprimento das atividades farmacêuticas (Brasil, 1973).

A Resolução CFF, $n^{\circ} 577$ de 25 de julho de 2013, estabeleceu além das funções do farmacêutico responsável técnico ou diretor técnico, que é o responsável pela realização, supervisão e coordenação de todos os serviços técnico-científicos do estabelecimento, como também o farmacêutico assistente técnico que é aquele subordinado hierarquicamente ao diretor técnico ou responsável técnico que, requerendo a assunção de farmacêutico assistente técnico de uma empresa ou de um estabelecimento, por meio dos formulários próprios do Conselho Regional de Farmácia (CRF), seja designado para complementar carga horária ou auxiliar o titular na prestação da assistência farmacêutica; e definiu ainda, o farmacêutico substituto designado perante o CRF para prestar assistência e responder tecnicamente nos casos de impedimentos ou ausências do farmacêutico diretor técnico ou farmacêutico responsável técnico, ou ainda do farmacêutico assistente técnico da empresa ou estabelecimento, respeitado o preconizado pela consolidação das Leis do Trabalho (CLT) ou acordo trabalhista (Conselho Federal de Farmácia, 2013).

A Lei $\mathrm{n}^{\circ}$ 13.021, de 8 de agosto de 2014, estabelece que a responsabilidade técnica e a presença do farmacêutico durante todo o tempo de funcionamento da farmácia comunitária são obrigatórias (Brasil, 2014). A responsabilidade técnica é uma atividade assumida na farmácia comunitária perante o Conselho Regional de Farmácia (CRF) da respectiva jurisdição e aos órgãos de vigilância sanitária. O farmacêutico responsável técnico tem a responsabilidade de realizar, supervisionar e coordenar todos os serviços técnico-científicos da empresa ou estabelecimento (Brasil, 2013).

Importante registrar que além do cadastro junto ao conselho da categoria, o farmacêutico precisa ter registro na Agência Nacional de Vigilância Sanitária (Anvisa) e na vigilância sanitária do município (Visa-Municipal). É o farmacêutico quem deve representar a farmácia comunitária em qualquer aspecto técnico-científico, responder pelos atos praticados por ele ou não e, fazer cumprir a legislação vigente. Suas atribuições podem ser divididas em clínicas e não clínicas. O farmacêutico técnico-assistencial engloba todas essas funções, o que pode prejudicar os serviços farmacêuticos ofertados aos utentes; ou seja, a atenção farmacêutica, ou cuidado farmacêutico pode ser prejudicada pelo acúmulo de funções (Correr et al., 2011; Cruz et al., 2020).

Quanto a percepção dos farmacêuticos sobre suas responsabilidades frente ao cumprimento dos marcos regulatórios em farmácias comunitárias privadas, observou-se que as atividades relativas ao funcionamento junto aos órgãos reguladores a exemplo da Vigilância Sanitária e da Agência Nacional de Vigilância Sanitária (ANVISA); tais como, a regulamentação da farmácia, certificados, liberação de funcionamento, entre outras, representação da empresa e/ou estabelecimento em todos os aspectos técnico-científicos e organização e guarda da documentação de funcionamento do estabelecimento, são, predominantemente, atribuídas ao farmacêutico técnico-assistencial. Outrossim, a manutenção das áreas internas e externas em boas condições físicas e estruturais são majoritariamente atribuídas ao farmacêutico técnico-gerencial (Tabela 1). 
Tabela 1 - Distribuição das atribuições farmacêuticas segundo o cumprimento das normas sanitárias

\begin{tabular}{|c|c|c|c|c|c|c|c|c|}
\hline \multirow[t]{2}{*}{ ATRIBUIÇÕES FARMACÊUTICAS } & \multicolumn{2}{|c|}{ FTG } & \multicolumn{2}{|c|}{ FTA } & \multicolumn{2}{|c|}{ FTA \& FTG } & \multicolumn{2}{|c|}{$\mathrm{P}$} \\
\hline & $\mathrm{n}$ & $\%$ & $\mathrm{n}$ & $\%$ & $\mathrm{n}$ & $\%$ & $\mathrm{n}$ & $\%$ \\
\hline $\begin{array}{lcr}\begin{array}{l}\text { Documentos de } \\
\text { estabelecimento } \\
\begin{array}{l}\text { funcionamento } \\
\text { autorização da ANVISA }\end{array}\end{array} & \begin{array}{l}\text { do } \\
\text { parutico }\end{array} & \text { para } \\
\end{array}$ & 11 & $18,6 \%$ & 29 & $49,1 \%$ & 12 & $20,3 \%$ & 7 & $11,8 \%$ \\
\hline $\begin{array}{l}\text { Representar a empresa e/ou estabelecimento } \\
\text { em todos os aspectos técnico-científicos }\end{array}$ & 11 & $18,6 \%$ & 25 & $42,3 \%$ & 20 & $33,9 \%$ & 3 & $5,0 \%$ \\
\hline $\begin{array}{l}\text { Organização e guarda da documentação de } \\
\text { funcionamento do estabelecimento }\end{array}$ & 14 & $23,7 \%$ & 34 & $57,6 \%$ & 9 & $15,2 \%$ & 2 & $3,3 \%$ \\
\hline $\begin{array}{l}\text { Manutenção das áreas internas e externas em } \\
\text { boas condições físicas e estruturais }\end{array}$ & 20 & $33,9 \%$ & 10 & $16,9 \%$ & 27 & $45,7 \%$ & 2 & $3,3 \%$ \\
\hline
\end{tabular}

FTG = Farmacêutico técnico gerencial. RTA = Farmacêutico técnico-assistencial. FTG \& FTA = Farmacêutico técnico-gerencial e Farmacêutico técnico-assistencial. $\mathrm{P}=$ Proprietário. Nota: $\mathrm{n}=$ Frequência absoluta. \% = Frequência relativa. Fonte: Percepção de farmacêuticos sobre suas funções técnicos-assistências e técnicos-gerenciais em farmácias comunitárias privadas (2021).

O Quadro 1 (Funções clínicas e não clínicas do farmacêutico), fundamenta-se nas diretrizes de estruturação de farmácias no âmbito do Sistema Único de Saúde (SUS), publicado em 2009 pelo Departamento de Assistência Farmacêutica e Insumos Estratégicos (DAF) do Ministério da Saúde (Brasil, 2009), classifica os serviços farmacêuticos em duas categorias: os serviços técnico-gerenciais (programação de medicamentos, processo de solicitação e armazenamento de medicamentos e atividades relacionadas com o descarte dos resíduos de serviços de saúde) e os serviços farmacêuticos técnico-assistenciais (dispensação, orientação farmacêutica, seguimento farmacoterapêutico, ações de educação em saúde e suporte técnico para a equipe de saúde).

Quadro 1 - Funções clínicas e não clínicas do farmacêutico.

\begin{tabular}{|c|c|}
\hline FUNÇÕES CLÍNICAS DO FARMACÊUTICO & FUNÇÕES NÃO CLÍNICAS DO FARMACÊUTICO \\
\hline Avaliação da prescrição apresentada pelo utente. & Aquisição e monitoramento do estoque da farmácia. \\
\hline Orientação sobre o uso correto, racional e seguro do medicamento. & $\begin{array}{l}\text { Executar, acompanhar e assegurar a aquisição dos medicamentos, bem } \\
\text { como receber e armazenar adequadamente os medicamentos, } \\
\text { promovendo a correta distribuição de medicamentos. }\end{array}$ \\
\hline Prescrição farmacêutica. & $\begin{array}{l}\text { Substituição de medicamento de referência por genérico, ou vice- } \\
\text { versa. }\end{array}$ \\
\hline Acompanhamento farmacoterapêutico do utente. & $\begin{array}{l}\text { Desenvolvimento do manual de boas práticas de distribuição de } \\
\text { medicamentos aos utentes. }\end{array}$ \\
\hline $\begin{array}{l}\text { Farmacovigilância para identificar, avaliar e monitorar eventos } \\
\text { adversos relacionados a medicamentos. }\end{array}$ & $\begin{array}{l}\text { Elaboração e implantação dos procedimentos operacionais que } \\
\text { regulamentam todas as atividades do estabelecimento. }\end{array}$ \\
\hline Administração de medicamentos injetáveis e de inaloterapia. & $\begin{array}{l}\text { Confecção de um Plano de Gerenciamento de Resíduos de Serviços de } \\
\text { Saúde (PGRSS), conforme orientações que constam na Resolução } \\
\text { Conama } \text { n }^{\circ} 358 / 05 \text { e na RDC/ANVISA n }{ }^{\circ} \text { 306/04. }\end{array}$ \\
\hline $\begin{array}{l}\text { Realização de ações de educação em saúde voltadas para a } \\
\text { comunidade. }\end{array}$ & $\begin{array}{l}\text { Realização e/ou supervisão de treinamento e capacitação de } \\
\text { funcionários. }\end{array}$ \\
\hline
\end{tabular}

Fonte: Percepção de farmacêuticos sobre suas funções técnicos-assistências e técnicos-gerenciais em farmácias comunitárias privadas (2021).

Quanto a atenção farmacêutica ou cuidado farmacêutico, 30 (50,8\%) dos farmacêuticos responderam ser uma atribuição do farmacêutico técnico-assistencial, 27 (45,7\%) responderam ser compartilhada entre os farmacêuticos técnico-assistenciais e técnico-gerenciais e $2(3,4 \%)$ responderam ser uma atribuição do farmacêutico técnico-gerencial (Figura 1). Tradicionalmente o cuidado na atenção aos utentes não vem tendo protagonismo no atendimento farmacêutico em farmácias comunitárias brasileiras. Neste contexto, o Conselho Federal de Farmácia publicou duas resoluções, a Resolução CFF nº 585 , de 29 de agosto de 2013 e a Resolução CFF n 586 de 29 de agosto de 2013, que regulamentam, respectivamente, as atribuições clínicas do farmacêutico e a prescrição farmacêutica, fortalecendo a atuação do farmacêutico, sendo reforçadas pela Lei n ${ }^{\circ} 13.021$, de 8 de agosto de 2014 , que dispõe sobre o exercício e a fiscalização das atividades farmacêuticas (Brasil, 2013; 2014). 
Figura 1 - Atenção Farmacêutica ou Cuidado Farmacêutico.

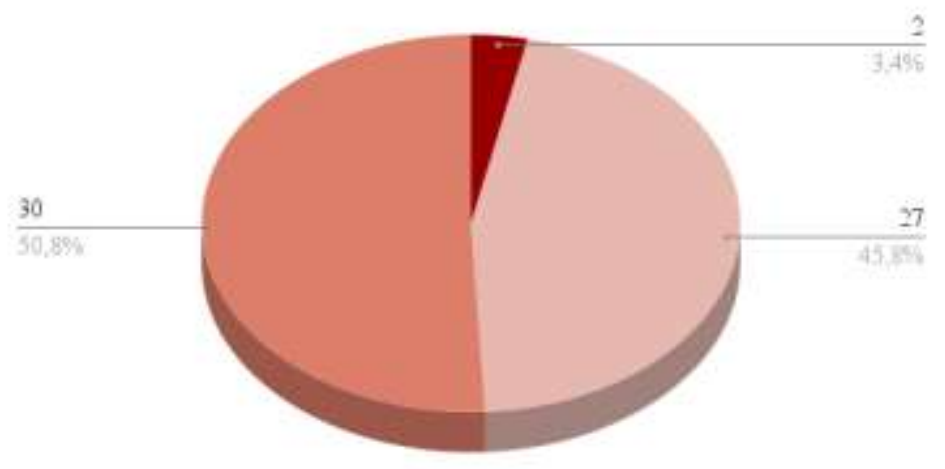

- Farmacêutico técnico-gerencial; Farmacêutico técnico-assistencial; Farmacêutico técnico-gerencial e técnico-assistencial. Fonte: Percepção de farmacêuticos sobre suas funções técnicos-assistências e técnicos-gerenciais em farmácias comunitárias privadas (2021).

Observa-se, que a partir da Lei n ${ }^{\circ} 13.021$, de 8 de agosto de 2014, a qual estabelece que as farmácias comunitárias são estabelecimentos de saúde, cresceu a procura por serviços farmacêuticos. A relação unicamente comercial vem dando espaço às ações de cuidado com a saúde, tendo como repercussão positiva uma maior procura por profissionais farmacêuticos e a valorização do mesmo. A participação efetiva do profissional farmacêutico coordenando os procedimentos de assistência à saúde prestados nas farmácias comunitárias é relevante; uma vez que a partir de suas orientações técnicas se alcança uma maior segurança e qualidade no atendimento ao utente. Reconhece-se, que o número de farmácias comunitárias privadas aumentou cerca de 6,3\%, elevando-se de 63.752 farmácias em 2007 para 67.753 farmácias em 2015; tendência que variou entre os distintos tipos de farmácias; ou seja, houve um aumento de $18 \%$ no número de farmácias de grandes redes quando comparada as farmácias independentes (Qato et al., 2017).

O uso de medicamentos precisa ser tratado com seriedade, uma vez que o uso incorreto pode gerar sérios problemas à saúde do utente e, com isso, trazer prejuízos financeiros à família e ao Estado. Assim sendo, faz-se necessário valorizar e dar reconhecimento ao farmacêutico pelos órgãos públicos e pela sociedade. Para isso, é necessária uma melhor interação do farmacêutico com o utente. A implantação de serviços farmacêuticos nas farmácias comunitárias não é tarefa simples; visto que, o farmacêutico termina exercendo dentro da empresa desvio de funções, o que acaba dificultando o Cuidado Farmacêutico. Infelizmente muitos empresários ainda não visualizaram nos serviços farmacêuticos a oportunidade para fidelizar utentes e assegurar a sustentabilidade da empresa (Cordina et al., 2008; Bastos \& Caetano; 2010; Oliveira et al., 2017; Cruz et al., 2020).

Adaptar-se ao mercado competitivo dos medicamentos, adequações estruturais (físicas) e organizacionais (comportamentais), são necessárias nas farmácias comunitárias para as manter ativas e competitivas. Em adição, as mudanças no comportamento empresarial, depende do perfil do farmacêutico, que deixou de ser um mero funcionário para que a empresa cumprisse as obrigações junto às agências reguladoras para sair do anonimato e interagir com os utentes, compartilhando seus conhecimentos técnico-científicos e fidelizando os mesmos aos serviços da empresa (Holdford, 2018). Moullin et al., (2016), reconhecem a importância dos aspectos relacionados a estrutura e organização da farmácia comunitária para a oferta de serviços farmacêuticos e sua relação com a sustentabilidade do empreendimento e a fidelização do utente.

Araújo et al. (2017) avaliaram as atividades de natureza clínica - entrevistando os responsáveis pelo aviamento dos medicamentos nas farmácias comunitárias -, e evidenciaram que dentre os 285 farmacêuticos, 206 não realizavam atividades relacionadas ao Cuidado Farmacêutico. Os principais motivos alegados pelos farmacêuticos para não realizar atividades clínicas foram: nunca ter sido solicitado e não dispor de espaço físico e de tempo suficiente. Além da falta de tempo, interesse do usuário e remuneração, são apontados pelos farmacêuticos como barreiras para o desenvolvimento de serviços clínicos para o utente 
(Farina \& Romano-Lieber, 2009; Dosea et al., 2016; Santos Júnior et al., 2018; El Hajj et al., 2016; Costa et al., 2017). Reconhece-se, que o usuário de medicamentos se comporta como mero consumidor, cultura essa que se constitui em barreira para a aproximação do farmacêutico com o público e, consequentemente, para a implementação de serviços farmacêuticos (Bastos \& Caetano 2010; Costa et al., 2017).

Em adição, uma grande dificuldade a ser superada pelos farmacêuticos comunitários é o seu distanciamento entre o farmacêutico e a população, o que dificulta os utentes sobre o seu real papel no apoio à farmacoterapia. Há, também, evidências sobre o despreparo dos farmacêuticos para realizar serviços clínicos, indicando deficiências em sua formação acadêmica (Reis et al., 2015; Zekan et al., 2017). Sobre isso, o Conselho Federal de Farmácia lançou o Programa de Suporte ao Cuidado Farmacêutico na Atenção Básica (ProFar), que tem como objetivo propagar conhecimento e desenvolver as habilidades necessárias para os farmacêuticos atuarem no Cuidado Farmacêutico, conceituado como todo serviço farmacêutico que é prestado centrado no utente e na promoção à saúde (Brasil, 2016). Na mesma direção, em 2017, as Diretrizes Curriculares Nacionais dos Cursos de Graduação em Farmácia foram atualizadas, incentivando uma formação que esteja na interface com a saúde pública e integrada ao Sistema Único de Saúde (Brasil, 2017).

$30(50,8 \%)$ respondentes responderam que oferecer orientação aos utentes quanto à eficácia dos medicamentos genéricos, $31(52,5 \%)$ que garantir a aplicação da intercambialidade farmacêutica, 23 (38,9\%) que promoção de ações em saúde, $22(37,2 \%)$ que supervisão técnica dos colaboradores atendentes, 38 (64,4\%) que observação do receituário na dispensação, 34 $(57,6 \%)$ que supervisão técnica e $27(45,7 \%)$ que orientação aos colaboradores atendentes sobre estimular o uso racional de medicamentos, são atribuições do farmacêutico técnico-assistencial (Tabela 2).

A farmácia comunitária, pelo espaço que ocupa no processo saúde-doença, é um lócus importante para a realização de práticas que fomentem o uso seguro e racional de medicamentos. A presença e a ação do farmacêutico nesses estabelecimentos se fundamentam no fato de que o uso com qualidade do medicamento requer a aplicação de um profundo conhecimento técnicocientífico sobre as suas características intrínsecas e extrínsecas e da relação benefício/risco da sua utilização; outrossim, eficácia do fármaco, efetividade dos medicamentos e eficiência do tratamento (Soler et al., 2018).

Sabe-se que serviços farmacêuticos prestados nas farmácias comunitárias possibilitam segurança e a melhoria na qualidade de vida dos utentes.

Tabela 2 - Distribuição das atribuições farmacêuticas segundo contexto de serviços clínicos.

\begin{tabular}{|c|c|c|c|c|c|c|c|c|}
\hline \multirow[t]{2}{*}{ ATRIBUIÇÕES FARMACÊUTICAS } & \multicolumn{2}{|c|}{ FTG } & \multicolumn{2}{|c|}{ FTA } & \multicolumn{2}{|c|}{ FTA \& FTG } & \multicolumn{2}{|c|}{$\mathrm{P}$} \\
\hline & $\mathrm{n}$ & $\%$ & $\mathrm{n}$ & $\%$ & $\mathrm{n}$ & $\%$ & $\mathrm{n}$ & $\%$ \\
\hline $\begin{array}{l}\text { Oferecer orientação aos utentes quanto à } \\
\text { eficácia dos medicamentos genéricos. }\end{array}$ & 3 & $5,0 \%$ & 30 & $50,8 \%$ & 25 & $42,3 \%$ & 1 & $1,6 \%$ \\
\hline $\begin{array}{l}\text { Garantir a aplicação da intercambialidade } \\
\text { farmacêutica. }\end{array}$ & 5 & $8,4 \%$ & 31 & $52,5 \%$ & 23 & $38,9 \%$ & 0 & $0,0 \%$ \\
\hline Promoção de ações em saúde & 8 & $13,5 \%$ & 23 & $38,9 \%$ & 25 & $42,3 \%$ & 3 & $5,0 \%$ \\
\hline $\begin{array}{l}\text { Supervisão técnica dos colaboradores } \\
\text { atendentes }\end{array}$ & 5 & $8,4 \%$ & 22 & $37,2 \%$ & 32 & $54,2 \%$ & 0 & $0,0 \%$ \\
\hline Observação do receituário na dispensação & 4 & $6,7 \%$ & 38 & $64,4 \%$ & 17 & $28,8 \%$ & 0 & $0,0 \%$ \\
\hline Supervisão técnica & 12 & $20,3 \%$ & 34 & $57,6 \%$ & 12 & $20,3 \%$ & 1 & $1,6 \%$ \\
\hline $\begin{array}{l}\text { Orientação aos colaboradores atendentes sobre } \\
\text { estimular o uso racional de medicamentos }\end{array}$ & 6 & $10,1 \%$ & 27 & $45,7 \%$ & 25 & $42,3 \%$ & 1 & $1,6 \%$ \\
\hline
\end{tabular}

FTG = Farmacêutico técnico-gerencial. RTA = Farmacêutico técnico-assistencial. FTG \& FTA = Farmacêutico técnico-gerencial e Farmacêutico técnico-assistencial. $\mathrm{P}=$ Proprietário. Nota: $\mathrm{n}=$ Frequência absoluta. $\%=$ Frequência relativa. Fonte: Percepção de farmacêuticos sobre suas funções técnicos-assistências e técnicos-gerenciais em farmácias comunitárias privadas (2021).

Os Serviços Farmacêuticos prestados - a exemplo do cuidado farmacêutico - deve considerar seu potencial de realizar atividades que incentivem o uso racional e seguro de medicamentos, com base em uma assistência farmacêutica humanizada e um atendimento respeitoso, ético e acolhedor com o utente (Oliveira et al., 2017). À vista disso, destaca-se que as práticas de 
Cuidado Farmacêutico com foco nos usuários beneficiam não somente os utentes, mas também otimiza e melhora a qualidade dos serviços prestados, proporcionando valorização e reconhecimento do profissional farmacêutico pela sociedade (Miranda Filho; Júnior; Montenegro, 2021). De acordo com Moullin et al. (2016), os serviços farmacêuticos públicos ou privados, incluem a realização de revisão de utilização de medicamentos e aconselhamento sobre o uso com qualidade dos medicamentos, visando promover uma melhor adesão a terapêutica, a efetividade do tratamento e melhoria da qualidade de vida do utente. As farmácias comunitária aplicam vacinas e fazem campanhas de promoção a saúde.

Muller (2019), registra que empresários de farmácias comunitárias no Brasil reconhecem um aumento na procura por serviços farmacêuticos e resultados positivos pós-implantação dos serviços farmacêuticos. A oferta dos serviços de Cuidado Farmacêutico acaba por ser um grande diferencial entre empresas e contribui significativamente para que os utentes façam o uso racional de medicamentos.

Com relação à orientação e supervisão dos colaboradores atendentes da farmácia (balconistas), observou-se menor participação do farmacêutico técnico-gerencial. Deste modo, $6(10.1 \%)$ farmacêuticos responderam que a função de orientar os colaboradores atendentes no processo de dispensação e orientações sobre o uso com qualidade de medicamentos é do farmacêutico técnico-gerencial; e 25 (42.3\%) responderam que é papel de ambos os farmacêuticos (Tabela 3).

Tabela 3 - Distribuição das atividades farmacêutica segundo orientação e supervisão dos colaboradores atendentes.

\begin{tabular}{|c|c|c|c|c|c|c|c|c|}
\hline \multirow{2}{*}{ ATRIBUIÇÕES FARMACÊUTICAS } & \multicolumn{2}{|c|}{ FTG } & \multicolumn{2}{|c|}{ FTA } & \multicolumn{2}{|c|}{ FTA \& FTG } & \multicolumn{2}{|c|}{$\mathrm{P}$} \\
\hline & $\mathrm{n}$ & $\%$ & $\mathrm{n}$ & $\%$ & $\mathrm{n}$ & $\%$ & $\mathrm{n}$ & $\%$ \\
\hline Supervisão dos colaboradores & 5 & $8,4 \%$ & 22 & $37,2 \%$ & 32 & $54,2 \%$ & 0 & $0,0 \%$ \\
\hline Orientação dos colaboradores & 6 & $10,1 \%$ & 27 & $45,7 \%$ & 25 & $42,3 \%$ & 1 & $1,6 \%$ \\
\hline $\begin{array}{l}\text { Supervisão dos funcionários, em relação ao } \\
\text { cumprimento das normas sanitárias. }\end{array}$ & 14 & $23,7 \%$ & 22 & $37,2 \%$ & 22 & $37,2 \%$ & 1 & $1,6 \%$ \\
\hline $\begin{array}{l}\text { Realizar e/ou supervisionar os treinamentos } \\
\text { iniciais e de atualização dos funcionários da } \\
\text { farmácia. }\end{array}$ & 16 & $27,1 \%$ & 26 & $44,0 \%$ & 14 & $23,7 \%$ & 3 & $5,0 \%$ \\
\hline
\end{tabular}

Legenda: FTG = Farmacêutico técnico-gerencial. RTA = Farmacêutico técnico-assistencial. FTG \& FTA = Farmacêutico técnico-gerencial e Farmacêutico técnico-assistencial. $\mathrm{P}=$ Proprietário. Nota: $\mathrm{n}=$ Frequência absoluta. $\%=$ Frequência relativa. Fonte: Percepção de farmacêuticos sobre suas funções técnicos-assistências e técnicos-gerenciais em farmácias comunitárias privadas (2021).

Quando se trata das orientações técnicas a respeito da dispensação de modo a garantir qualidade e segurança ao tratamento do utente, os colaboradores atendentes (balconistas) necessitam do conhecimento e da supervisão do farmacêutico. O farmacêutico deve assumir o papel do instrutor; ou seja, um orientador capaz de desenvolver as competências necessárias para quem pretende fazer um atendimento diferenciado.

O processo de esclarecimento e conscientização é fundamental para a mudança de comportamentos e atitudes da sociedade, refletindo na redução dos danos causados pelo uso irracional de medicamentos. Ainda nesta direção, os colaboradores atendentes (balconistas) tem fundamental importância, uma vez que, nem sempre os farmacêuticos estão disponíveis para atendimento no balcão. Aqui é relevante recordar do Modelo da Kaiser Permanente que explicita a importância de ações relacionadas a promoção da saúde, prevenção de doenças, autocuidado suportado, gestão da patologia e gestão de caso (Mendes, 2012; Choe et al., 2018; Cruz et al., 2020).

Quanto a percepção sobre a elaboração do Manual de Boas Práticas Farmacêuticas e de Procedimentos Operacionais Padrão - POP's (Tabela 4), observa-se que referem ser atribuições dos farmacêuticos técnico-assistenciais:

- $34(57,6 \%)$ elaborar o manual de boas práticas farmacêuticas.

- $34(57,6 \%)$ a prestação de serviços de orientação farmacêutica e seguimento farmacoterapêutico.

- $34(57,6 \%)$ a manutenção das condições higiênicas e sanitárias adequadas de cada ambiente e a dispensação dos medicamentos.

- $35(59,3 \%)$ a destinação dos produtos com prazos de validade vencidos. 
- $\quad 34(57,6 \%)$ a aquisição, recebimento e armazenamento dos produtos sujeitos às normas de vigilância sanitária. Estes achados fazem refletir sobre os equívocos de compreensão quanto aos conceitos ou atribuições de farmacêutico técnico-gerencial e técnico-assistencial.

Tabela 4 - Distribuição das atribuições farmacêuticas segundo os procedimentos operacionais padrão

\begin{tabular}{|c|c|c|c|c|c|c|c|c|}
\hline \multirow{2}{*}{ ATRIBUIÇÕES FARMACÊUTICAS } & \multicolumn{2}{|c|}{ FTG } & \multicolumn{2}{|c|}{ FTA } & \multicolumn{2}{|c|}{ FTA \& FTG } & \multicolumn{2}{|c|}{$\mathrm{P}$} \\
\hline & $\mathrm{n}$ & $\%$ & $\mathrm{n}$ & $\%$ & $\mathrm{n}$ & $\%$ & $\mathrm{n}$ & $\%$ \\
\hline Manual de Boas Práticas Farmacêuticas & 9 & $15,2 \%$ & 34 & $57,6 \%$ & 5 & $8,4 \%$ & 11 & $18,6 \%$ \\
\hline $\begin{array}{l}\text { POP - Prestação de serviços de orientação } \\
\text { farmacêutica } \\
\text { farmacoterapêutico. }\end{array}$ & 9 & $15,2 \%$ & 34 & $57,6 \%$ & 6 & $10,1 \%$ & 10 & $16,9 \%$ \\
\hline $\begin{array}{l}\text { POP - Manutenção das condições higiênicas e } \\
\text { sanitárias adequadas de cada ambiente. }\end{array}$ & 10 & $16,9 \%$ & 34 & $57,6 \%$ & 5 & $8,4 \%$ & 10 & $16,9 \%$ \\
\hline $\begin{array}{l}\text { POP - Aquisição, recebimento } \mathrm{e} \\
\text { armazenamento dos produtos sujeitos às } \\
\text { normas de vigilância sanitária. }\end{array}$ & 9 & $15,2 \%$ & 34 & $57,6 \%$ & 7 & $11,8 \%$ & 9 & $15,2 \%$ \\
\hline POP - Dispensação dos medicamentos. & 8 & $13,5 \%$ & 34 & $57,6 \%$ & 8 & $13,5 \%$ & 9 & $15,2 \%$ \\
\hline $\begin{array}{l}\text { POP - Destino dos produtos com prazos de } \\
\text { validade vencidos. }\end{array}$ & 10 & $16,9 \%$ & 35 & $59,3 \%$ & 5 & $8,4 \%$ & 9 & $15,2 \%$ \\
\hline
\end{tabular}

Legenda: FTG = Farmacêutico técnico-gerencial. RTA = Farmacêutico técnico-assistencial. FTG \& FTA = Farmacêutico técnico-gerencial e Farmacêutico técnico-assistencial. $\mathrm{P}=$ Proprietário. Nota: $\mathrm{n}=$ Frequência absoluta. $\%=$ Frequência relativa. Fonte: Percepção de farmacêuticos sobre suas funções técnicos-assistências e técnicos-gerenciais em farmácias comunitárias privadas (2021).

A Resolução da Diretoria Colegiada (RDC) da Agência Nacional de Vigilância Sanitária (ANVISA) n 44 , de 17 de agosto de 2009, que dispõe sobre boas práticas farmacêuticas para o controle sanitário do funcionamento, da dispensação e da comercialização de produtos e da prestação de serviços farmacêuticos em farmácias comunitárias; estabelece, também, a importância do treinamento de todos os profissionais envolvidos na realização dos serviços farmacêuticos. Outrossim, de acordo com a Portaria do Ministério da Saúde GM/MS nº 344, de 12 de maio de 1998, as substâncias sujeitas a controle especial, bem como os medicamentos que são formulados a partir delas, devem ser guardados sob chave ou outro dispositivo que ofereça segurança, em local exclusivo para este fim, sob responsabilidade do farmacêutico. Ainda, a dispensação deve ser feita exclusivamente por farmacêuticos, sendo proibida a delegação dessa atividade a outros funcionários do estabelecimento (Brasil, 1998). Em adição, com a publicação da RDC/ANVISA no 20, de 5 de maio de 2011, os medicamentos contendo substâncias classificadas como antimicrobianos e sujeitos a prescrição médica passaram a ser dispensados com a retenção de receita pela farmácia comunitária (Brasil, 2011).

Sabe-se que a escrituração da venda deve ser feita onde há dispensação de medicamentos sujeitos a controle especial e medicamentos contendo substâncias classificadas como antimicrobianos. Nas farmácias comunitárias privadas a escrituração é feita através do Sistema Nacional de Gerenciamento de Produtos Controlados (SNGPC). O acesso ao SNGPC é de responsabilidade do farmacêutico técnico-assistencial credenciado junho à Agência Nacional de Vigilância Sanitária. Na ausência do farmacêutico técnico-assistencial, a escrituração pode ser feita pelo farmacêutico substituto, desde que este também esteja cadastrado no sistema (Brasil, 2014).

Observou-se que o farmacêutico técnico-assistencial é quem exerce as atribuições ligadas ao controle de medicamentos sujeitos a controle especial e medicamentos contendo substâncias classificadas como antimicrobianos. Relativamente ao Sistema Nacional de Gerenciamento de Produtos Controlados (SNGPC), impera a atuação do farmacêutico técnico-assistencial, e a participação do farmacêutico técnico-gerencial, tanto em acesso quanto em movimentação do sistema, não é comum. 7 (11,8\%) dos farmacêuticos revelaram que a movimentação do SNGPC é incumbência do farmacêutico técnico-gerencial; e 4 (6,7\%) denotaram que este é um encargo de ambos os farmacêuticos (Tabela 5). 
Tabela 5 - Distribuição das atribuições farmacêuticas segundo o controle de medicamentos sujeitos a controle especial

\begin{tabular}{|c|c|c|c|c|c|c|c|c|}
\hline \multirow{2}{*}{ ATRIBUIÇÕES FARMACÊUTICAS } & \multicolumn{2}{|c|}{ FTG } & \multicolumn{2}{|c|}{ FTA } & \multicolumn{2}{|c|}{ FTA \& FTG } & \multicolumn{2}{|c|}{$\mathrm{P}$} \\
\hline & $\mathrm{n}$ & $\%$ & $\mathrm{n}$ & $\%$ & $\mathrm{n}$ & $\%$ & $\mathrm{n}$ & $\%$ \\
\hline $\begin{array}{l}\text { Guarda de documentos fiscais referente à } \\
\text { compra, venda, transferência ou devolução de } \\
\text { medicamentos antimicrobianos }\end{array}$ & 8 & $13,5 \%$ & 35 & $59,3 \%$ & 11 & $18,6 \%$ & 5 & $8,4 \%$ \\
\hline Movimentação no sistema SNGPC & 7 & $11,8 \%$ & 47 & $79,6 \%$ & 4 & $6,7 \%$ & 1 & $1,6 \%$ \\
\hline Acesso ao SNGPC & 5 & $8,4 \%$ & 40 & $67,8 \%$ & 12 & $20,3 \%$ & 2 & $3,3 \%$ \\
\hline $\begin{array}{l}\text { Controle da chave do armário dos } \\
\text { medicamentos controlados. }\end{array}$ & 6 & $10,1 \%$ & 31 & $52,5 \%$ & 21 & $35,5 \%$ & 1 & $1,6 \%$ \\
\hline $\begin{array}{l}\text { Organização das substâncias e medicamentos } \\
\text { sujeitos a controle especial, existentes nos } \\
\text { estabelecimentos, guardados sob chave ou } \\
\text { outro dispositivo que ofereça segurança, em } \\
\text { local exclusivo para este fim. }\end{array}$ & 5 & $8,4 \%$ & 37 & $62,7 \%$ & 17 & $28,8 \%$ & 0 & $0,0 \%$ \\
\hline $\begin{array}{l}\text { Escrituração e guarda de documentos de } \\
\text { substâncias e medicamentos sujeitos a controle } \\
\text { especial }\end{array}$ & 8 & $13,5 \%$ & 39 & $66,1 \%$ & 12 & $20,3 \%$ & 0 & $0,0 \%$ \\
\hline $\begin{array}{l}\text { Organização, separação em armários } \\
\text { trancados os remédios controlados vencidos }\end{array}$ & 10 & $16,9 \%$ & 34 & $57,6 \%$ & 15 & $25,4 \%$ & 0 & $0,0 \%$ \\
\hline $\begin{array}{l}\text { Fiscalização das receitas de antimicrobianos, } \\
\text { segundo as normas de prescrição }\end{array}$ & 3 & $5,0 \%$ & 33 & $55,9 \%$ & 23 & $38,9 \%$ & 0 & $0,0 \%$ \\
\hline Controle dos antimicrobianos & 5 & $8,4 \%$ & 39 & $66,1 \%$ & 15 & $25,4 \%$ & 0 & $0,0 \%$ \\
\hline
\end{tabular}

FTG = Farmacêutico técnico-gerencial. RTA = Farmacêutico técnico-assistencial. FTG \& FTA = Farmacêutico técnico-gerencial e Farmacêutico técnico-assistencial. $\mathrm{P}=$ Proprietário. Nota: $\mathrm{n}=$ Frequência absoluta. $\%=$ Frequência relativa. Fonte: Percepção de farmacêuticos sobre suas funções técnicos-assistências e técnicos-gerenciais em farmácias comunitárias privadas (2021).

O armazenamento correto do medicamento é fator indispensável para garantir que a sua qualidade permaneça dentro dos padrões ideais; uma das etapas do ciclo da assistência farmacêutica. Assim sendo, os farmacêuticos e/ou colaboradores atendentes da farmácia (balconistas) devem orientar os utentes relativamente à guarda e o uso correto de medicamentos, para que este seja preservado com qualidade até o momento do consumo.

No tocante à gestão técnica (logística) do medicamento nas farmácias comunitárias, observa-se maior concentração das atividades para o farmacêutico técnico-assistencial (Tabela 6). Já em relação às atribuições de programação e solicitação/requisição de medicamentos se observa compartilhamento de atribuições, entre farmacêutico técnico-gerencial, técnico-assistencial e proprietário. A aquisição (compra) do medicamento é de responsabilidade do proprietário do estabelecimento. Sabe-se, contudo, que em se tratando da qualidade de medicamentos o farmacêutico seria a pessoa mais indicada a selecionar os produtos com melhor segurança e qualidade. 
Tabela 6 - Distribuição das atribuições farmacêuticas segundo a gestão técnica dos medicamentos na farmácia comunitária

\begin{tabular}{|c|c|c|c|c|c|c|c|c|}
\hline \multirow{2}{*}{ ATRIBUIÇÕES FARMACÊUTICAS } & \multicolumn{2}{|c|}{ FTG } & \multicolumn{2}{|c|}{ FTA } & \multicolumn{2}{|c|}{ FTA \& FTG } & \multicolumn{2}{|c|}{$\mathrm{P}$} \\
\hline & $\mathrm{n}$ & $\%$ & $\mathrm{n}$ & $\%$ & $\mathrm{n}$ & $\%$ & $\mathrm{n}$ & $\%$ \\
\hline $\begin{array}{l}\text { Organização e manutenção do cadastro } \\
\text { atualizado com dados técnico-científicos das } \\
\text { drogas, fármacos e medicamentos disponíveis } \\
\text { na farmácia. }\end{array}$ & 11 & $18,6 \%$ & 36 & $61,0 \%$ & 6 & $10,1 \%$ & 6 & $10,1 \%$ \\
\hline Programação de medicamentos & 14 & $23,7 \%$ & 17 & $28,8 \%$ & 13 & $22,0 \%$ & 15 & $25,4 \%$ \\
\hline Solicitação/requisição de medicamentos & 16 & $27,1 \%$ & 7 & $11,8 \%$ & 15 & $25,4 \%$ & 21 & $35,5 \%$ \\
\hline $\begin{array}{l}\text { Gestão de qualidade de medicamentos em área } \\
\text { de circulação restrita aos funcionários }\end{array}$ & 7 & $11,8 \%$ & 28 & $47,4 \%$ & 21 & $35,5 \%$ & 3 & $5,0 \%$ \\
\hline $\begin{array}{l}\text { Gestão de qualidade de medicamentos e } \\
\text { produtos de circulação comum }\end{array}$ & 5 & $8,4 \%$ & 16 & $27,1 \%$ & 35 & $59,3 \%$ & 3 & $5,0 \%$ \\
\hline $\begin{array}{l}\text { Fiscalização do estado de conservação dos } \\
\text { medicamentos e produtos }\end{array}$ & 5 & $8,4 \%$ & 27 & $45,7 \%$ & 26 & $44,0 \%$ & 1 & $1,6 \%$ \\
\hline $\begin{array}{l}\text { Retirada de produtos e medicamentos que } \\
\text { apresentem problemas e/ou irregularidades da } \\
\text { área de dispensação ao público e comunicado } \\
\text { ao Serviço de Vigilância Sanitária para as } \\
\text { providências cabíveis, em especial aos } \\
\text { relacionados para interdição cautelar e/ ou } \\
\text { inutilização. }\end{array}$ & 10 & $16,9 \%$ & 24 & $40,6 \%$ & 23 & $38,9 \%$ & 2 & $3,3 \%$ \\
\hline Controle de temperatura. & 5 & $8,4 \%$ & 32 & $54,2 \%$ & 20 & $33,9 \%$ & 2 & $3,3 \%$ \\
\hline $\begin{array}{l}\text { Garantir o bom estado de conservação de } \\
\text { medicamentos termolábeis }\end{array}$ & 3 & $5,0 \%$ & 38 & $64,4 \%$ & 17 & $28,8 \%$ & 1 & $1,6 \%$ \\
\hline
\end{tabular}

FTG = Farmacêutico técnico gerencial. RTA = Farmacêutico técnico-assistencial. FTG \& FTA = Farmacêutico técnico-gerencial e Farmacêutico técnicoassistencial. $\mathrm{P}=$ Proprietário. Nota: $\mathrm{n}=$ Frequência absoluta. \% = Frequência relativa. Fonte: Percepção de farmacêuticos sobre suas funções técnicos-assistências e técnicos-gerenciais em farmácias comunitárias privadas (2021).

Quanto ao Plano de Gerenciamento de Resíduos de Serviços de Saúde (PGRSS) nas farmácias comunitárias privadas, $29(49,15 \%)$ dos farmacêuticos evidenciaram ser competência do farmacêutico técnico-assistencial; em contrapartida 11 $(18,64 \%)$ atribuíram o cargo ao farmacêutico técnico-gerencial; 12 (20,34\%) responderam que é domínio de ambos os farmacêuticos; e $7(11,86 \%)$ responderam que é função do proprietário do estabelecimento (Figura 2).

Figura 2 - Gerenciamento de resíduos de serviços de saúde.

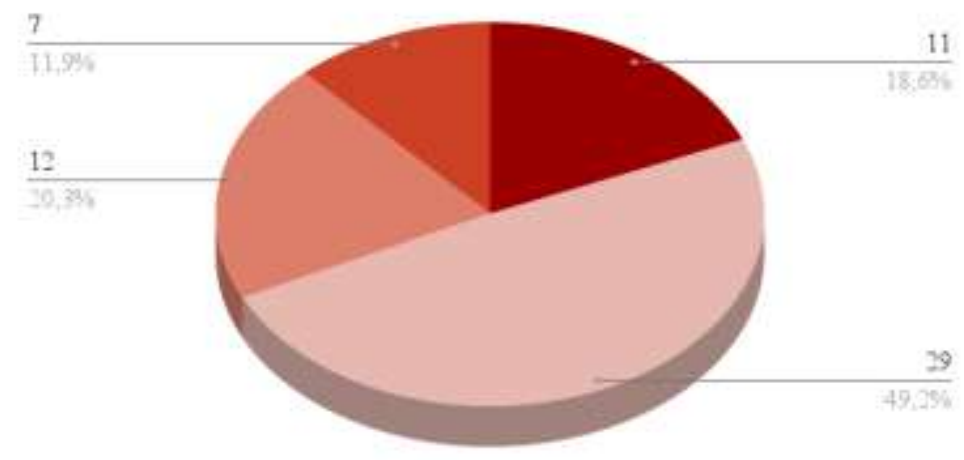

— Farmacêutico técnico-gerencial; $₫$ Farmacêutico técnico-assistencial; $₫$ Farmacêutico técnico-gerencial e técnico-assistencial; $₫$ Proprietário. Fonte: Percepção de farmacêuticos sobre suas funções técnicos-assistências e técnicos-gerenciais em farmácias comunitárias privadas (2021).

Segundo a Resolução Conama ${ }^{\circ}$ 358, de 05 de abril de 2005 e a RDC/ANVISA n 306, de 7 de dezembro de 2004, toda farmácia comunitária deve possuir um Programa de Gerenciamento dos Resíduos de Serviços de Saúde, pois é responsável pelo resíduo, desde a geração até a disposição final. Esse documento deverá ser elaborado por profissional de nível superior, 
habilitado pelo seu conselho de classe, com Anotação de Responsabilidade Técnica e Certificado de Responsabilidade Técnica; ou seja, no caso das farmácias comunitárias deverá ser elaborado e implantado pelo farmacêutico (Brasil, 2001).

A gerência e/ou gestão é uma das habilidades que o farmacêutico dos tempos atuais tem que ter. Ele deve administrar eficientemente recursos humanos, físicos, financeiros e informacionais. São atribuições que devem nortear as ações na sua prática profissional. As grandes redes de farmácias comunitárias se adaptaram a este novo cenário, principalmente para diminuir os custos de mão-de-obra, não necessitando contratar um administrador ou outro profissional da área administrativa para exercer esta função. Para o farmacêutico, esta nova atribuição proporcionou maior autonomia e responsabilidade na farmácia comunitária, numa posição hierárquica de maior prestígio e poder. Por outro lado, acumulou funções que antes não exercia, para as quais, muitas vezes, não possui formação técnica adequada.

As atividades administrativas do farmacêutico na farmácia comunitária privada apresentadas (Tabela 7), demonstram que as atividades relacionadas ao processo de gerência são, majoritariamente, do farmacêutico técnico-gerencial: 8 (13,5\%) contagem física dos estoques, 27 (45,7\%) abrir o estabelecimento, 27 (45,7\%) abertura e fechamento de caixa, 33 (55,9\%) reunir equipe para divulgar os desafios/metas, 25 (42,3\%) verificar falta de produtos nas prateleiras da área de livre circulação (segurança), 27 (45,7\%) orientar a equipe em relação a organização da loja, 31 (52,5\%) atender as reclamações de utentes, participar da troca de produtos, estorno de cartão de crédito e débito, cancelamento de itens, emissão de nota de crédito, 20 $(33,9 \%)$ recebimento de produtos, $31(52,5 \%)$ precificação dos produtos da área de livre circulação, 34 (57,6\%) gerenciamento de custos do estabelecimento (verificação das variações mensais dos custos fixos da loja: luz, água, materiais de limpeza etc.), $32(54,2 \%)$ problemas em relação ao fechamento do estabelecimento e $32(54,2 \%)$ avaliação de desempenho dos funcionários.

Tabela 7 - Distribuição das atribuições farmacêuticas segundo as atividades administrativas do farmacêutico na farmácia comunitária.

\begin{tabular}{|c|c|c|c|c|c|c|c|c|}
\hline \multirow{2}{*}{ ATRIBUIÇÕES FARMACÊUTICAS } & \multicolumn{2}{|c|}{ FTG } & \multicolumn{2}{|c|}{ FTA } & \multicolumn{2}{|c|}{ FTA \& FTG } & \multicolumn{2}{|c|}{$\mathrm{P}$} \\
\hline & $\mathrm{n}$ & $\%$ & $\mathrm{n}$ & $\%$ & $\mathrm{n}$ & $\%$ & $\mathrm{n}$ & $\%$ \\
\hline Contagem física dos estoques. & 8 & $13,5 \%$ & 33 & $55,9 \%$ & 17 & $28,8 \%$ & 1 & $1,6 \%$ \\
\hline Abrir o estabelecimento & 27 & $45,7 \%$ & 8 & $13,5 \%$ & 7 & $11,8 \%$ & 17 & $28,8 \%$ \\
\hline Abertura e fechamento de caixa & 27 & $45,7 \%$ & 6 & $10,1 \%$ & 10 & $16,9 \%$ & 16 & $27,1 \%$ \\
\hline Reunir equipe para divulgar os desafios/metas & 33 & $55,9 \%$ & 4 & $6,7 \%$ & 8 & $13,5 \%$ & 14 & $23,7 \%$ \\
\hline $\begin{array}{l}\text { Verificar falta de produtos nas prateleiras da } \\
\text { área de livre circulação (segurança) }\end{array}$ & 25 & $42,3 \%$ & 10 & $16,9 \%$ & 15 & $25,4 \%$ & 9 & $15,2 \%$ \\
\hline $\begin{array}{l}\text { Orientar a equipe em relação a organização da } \\
\text { Loja }\end{array}$ & 27 & $45,7 \%$ & 7 & $11,8 \%$ & 22 & $37,2 \%$ & 3 & $5,0 \%$ \\
\hline $\begin{array}{l}\text { Atender as reclamações de utentes, participar } \\
\text { da troca de produtos, estorno de cartão de } \\
\text { crédito e débito, cancelamento de itens, } \\
\text { emissão de nota de crédito }\end{array}$ & 31 & $52,5 \%$ & 6 & $10,1 \%$ & 10 & $16,9 \%$ & 12 & $20,3 \%$ \\
\hline Recebimento de produtos & 20 & $33,9 \%$ & 7 & $11,8 \%$ & 22 & $37,2 \%$ & 10 & $16,9 \%$ \\
\hline $\begin{array}{l}\text { Precificação dos produtos da área de livre } \\
\text { circulação }\end{array}$ & 31 & $52,5 \%$ & 8 & $13,5 \%$ & 10 & $16,9 \%$ & 10 & $16,9 \%$ \\
\hline $\begin{array}{l}\text { Gerenciamento de custos do estabelecimento } \\
\text { (verificação das variações mensais dos custos } \\
\text { fixos da loja: luz, água, materiais de limpeza } \\
\text { etc.) }\end{array}$ & 34 & $57,6 \%$ & 2 & $3,3 \%$ & 2 & $3,3 \%$ & 21 & $35,5 \%$ \\
\hline $\begin{array}{l}\text { Problemas em relação ao fechamento do } \\
\text { estabelecimento }\end{array}$ & 32 & $54,2 \%$ & 7 & $11,8 \%$ & 7 & $11,8 \%$ & 13 & $22,0 \%$ \\
\hline Avaliação de desempenho dos funcionários & 32 & $54,2 \%$ & 8 & $13,5 \%$ & 7 & $11,8 \%$ & 12 & $20,3 \%$ \\
\hline
\end{tabular}

Legenda: FTG = Farmacêutico técnico-gerencial. RTA = Farmacêutico técnico-assistencial. FTG \& FTA = Farmacêutico técnico-gerencial e Farmacêutico técnico-assistencial. $\mathrm{P}=$ Proprietário. Nota: $\mathrm{n}=$ Frequência absoluta. \% = Frequência relativa. Fonte: Percepção de farmacêuticos sobre suas funções técnicos-assistências e técnicos-gerenciais em farmácias comunitárias privadas (2021).

A percepção dos farmacêuticos comunitários quanto a sua prática profissional é observada, em maior frequência, estarem relacionadas as atividades técnico-gerenciais. As atividades técnico-assistenciais; em especial aquelas relacionados ao cuidado farmacêutico são menos referidas; indicando que o envolvimento dos farmacêuticos em atividades de saúde pública e/ou 
coletiva são menos frequentes. Outrossim, reconhece-se que a presença de um único farmacêutico realizando atividades técnicogerencias e técnico-assistenciais é inefetiva e ineficientes.

Cruz et al. (2020), ao sintetizarem evidências sobre intervenções farmacêuticas que proporcionam aos utentes de farmácia comunitária privada tratamentos eficientes e com a melhoria da qualidade de vida - por meio de uma revisão sistemática - constataram a redução da prescrição de medicamentos potencialmente inapropriados, melhoria do uso de medicamentos apropriados e seguros, melhoria da adesão ao tratamento, redução de eventos adversos a medicamentos, de interações medicamentos-medicamentos e de resultados negativos em saúde associados a medicamentos, redução de consultas ambulatoriais, de visitas a serviços de urgências e emergências, de internações hospitalares, de morbidade, mortalidade, melhoria do estado de saúde, da qualidade de vida e redução de custos de medicamentos. Por fim, seus achados quanto as intervenções farmacêuticas (profissionais, organizacionais, financeiras, governamentais e multifacetadas) permitem afirmar que há evidências quanto a melhoria de desfechos clínicos, de acesso e equidade aos serviços, epidemiológicos, humanísticos e econômicos advindos de serviços relacionados ao cuidado farmacêutico.

A farmácia comunitária ocupa um importante espaço no cenário da saúde pública brasileira, como local de dispensação de medicamentos e de contínua promoção da saúde da população. Nelas, o usuário busca, através da obtenção de produtos, prescritos ou não, o restabelecimento da sua saúde. Entretanto, ainda que o medicamento seja de fundamental importância para o paciente, tornando-se um componente estratégico na terapêutica e na manutenção de melhores condições de vida do indivíduo, é fundamental que não nos esqueçamos da necessidade de fornecer à sociedade informações seguras que minimizem o risco à saúde, que pode ser causado se o medicamento não for utilizado de modo adequado, efetivo e seguro.

\section{Aplicação}

Reflexionar sobre a necessidade de harmonizar as atribuições dos farmacêuticos técnico-gerenciais e técnicoassistenciais nas farmácia comunitárias privadas.

\section{Limitação, dificuldades e viés}

Número limitado de farmacêuticos respondentes. A não caracterização da amostra quanto a idade, sexo/gênero, instituição de formação acadêmica, tempo de formação, pós-graduação e faixa salarial. Dificuldades de acesso a informações sobre os farmacêuticos do estado do Pará, em função das regras estabelecidas pela assessoria jurídica do Conselho Regional de Farmácia do Estado do Pará (CRF-PA), por conta dos sigilos de dados. Potencial viés quanto ao grau de conhecimento e compreensão do respondente sobre os termos e marcos regulatórios utilizados.

\section{Considerações Finais}

A investigação identificou atribuições e funções dos farmacêuticos como técnicos-gerenciais e como técnicosassistenciais em farmácias comunitárias privadas. Observa-se, conflitos quanto à compreensão do papel dos farmacêuticos como técnicos-gerenciais e como técnicos-assistenciais; a exemplo das atividades de gestão e do cuidado farmacêutico. Infere-se, que não há harmonização das atribuições e funções dos farmacêuticos como técnicos-gerenciais e como técnicos-assistenciais nas farmácias comunitárias privadas.

Recomenda-se, para trabalhos futuros, a caracterização dos farmacêuticos quanto a idade, sexo/gênero, instituição de formação acadêmica, tempo de formação, pós-graduação e faixa salarial. 


\section{Contribuições dos autores}

DSMF, LHCM conceberam o desenho da pesquisa em conjunto com RNC, LMDQ, MMBP e OS. DSMF e LHCM aplicaram os instrumentos de investigação e escreveram o artigo sob a supervisão de RNC, LMDQ, MMBP e OS. Os autores leram e aprovaram a versão final do documento. O conteúdo do trabalho é de exclusiva responsabilidade individual dos autores.

\section{Declaração de conflito de interesse}

Os autores declaram que a pesquisa foi conduzida na ausência de quaisquer relações comerciais ou financeiras que possam ser interpretados como um potencial conflito de interesse.

\section{Referências}

Araújo, P. S., Costa, E. A., Guerra Junior, A. A., Acurcio, F. d. A., Guibu, I. A., Álvares, J., Costa, K. S., Karnikowski, M. G. d. O., Soeiro, O. M., \& Leite, S. N. (2017). Pharmaceutical care in Brazil's primary health care. Revista de Saúde Pública, 51(suppl.2). https://doi.org/10.11606/s1518-8787.2017051007109

Bastos, C. R. G., \& Caetano, R. (2010). As percepções dos farmacêuticos sobre seu trabalho nas farmácias comunitárias em uma região do estado do Rio de Janeiro. Ciênc. saúde coletiva. 15(3): 3541-3550. https://doi.org/10.1590/S1413-81232010000900029

Brasil (2001). Conselho Federal de Farmácia. Resolução 357, de 20 de abril de 2001. Aprova o regulamento técnico das boas práticas de farmácia. Brasília. Distrito Federal. RES 339_453 - páginas 823_1232.indd (cff.org.br)

Brasil. (1973). Agência Nacional de Vigilância Sanitária. Lei no 5.991, de 17 de dezembro de 1973. Dispõe sobre o Controle Sanitário do Comércio de Drogas, Medicamentos, Insumos Farmacêuticos e Correlatos, e dá outras Providências. Brasília. Distrito Federal. Diário Oficial da República Federativa do Brasil. L5991 (planalto.gov.br)

Brasil. (1998). Ministério da Saúde. Portaria GM/MS n 344, de 12 de maio de 1998. Aprova o Regulamento Técnico sobre substâncias e medicamentos sujeitos a controle especial. Brasília. Distrito Federal. Diário Oficial da República Federativa do Brasil. Ministério da Saúde (saude.gov.br)

Brasil. (2004). Agência Nacional de Vigilância Sanitária. Resolução da Diretoria Colegiada n 306, de 7 de dezembro de 2004 . Dispõe sobre o Regulamento Técnico para o gerenciamento de resíduos de serviços de saúde. Brasília. Distrito Federal. Diário Oficial da República Federativa do Brasil. Ministério da Saúde (saude.gov.br)

Brasil. (2005). Conselho Nacional de Meio Ambiente. Resolução Conama n 358 de 29 abril de 2005. Dispõe sobre o tratamento e a disposição final dos resíduos dos serviços de saúde e dá outras providências. Conama. avulso.job (as.org.br)

Brasil. (2009). Agência Nacional de Vigilância Sanitária. Resolução no 44, de 17 de agosto de 2009. Dispõe sobre Boas Práticas Farmacêuticas para o controle sanitário do funcionamento, da dispensação e da comercialização de produtos e da prestação de serviços farmacêuticos em farmácias e drogarias e dá outras providências, Brasília: Agência Nacional de Vigilância Sanitária - ANVISA. Ministério da Saúde (saude.gov.br)

Brasil. (2011). Agência Nacional de Vigilância Sanitária. Resolução no 20, de 5 de maio de 2011. Dispõe sobre o controle de medicamentos à base de substâncias classificadas como antimicrobianos, de uso sob prescrição, isoladas ou em associação. Brasília. Distrito Federal. Diário Oficial da República Federativa do Brasil. Ministério da Saúde (saude.gov.br)

Brasil. (2012). Conselho Nacional de Saúde. Resolução no 466 de 12 de dezembro de 2012. Aprova as diretrizes e normas regulamentadoras de pesquisas envolvendo seres humanos. Brasília. Distrito Federal. Ministério da Saúde (saude.gov.br)

Brasil. (2012). Ministério da Saúde. Secretaria de Ciência, Tecnologia e Insumos Estratégicos. Departamento de Ciência e Tecnologia. Diretrizes metodológicas: preparação de revisão sistemática e metanálise de ensaios randomizados. Brasília: Editora do Ministério da Saúde, 2012. 92 p.: il. - (Série A: Normas e Manuais Técnicos).

Brasil. (2013). Conselho Federal de Farmácia. Resolução nº 557 de 25 de julho de 2013. Dispõe sobre a direção técnica ou responsabilidade técnica de empresas ou estabelecimentos que dispensam, comercializam, fornecem e distribuem produtos farmacêuticos, cosméticos e produtos para a saúde.. Brasília. Distrito Federal. Diário Oficial da República Federativa do Brasil.

Brasil. (2013). Conselho Federal de Farmácia. Resolução no 585 de 29 de agosto de 2013. Regulamenta as atribuições clínicas do farmacêutico e dá outras providências. Brasília. Distrito Federal. Diário Oficial da República Federativa do Brasil.

Brasil. (2013). Conselho Federal de Farmácia. Resolução no 586 de 29 de agosto de 2013. Regula a prescrição farmacêutica e dá outras providências. Brasília. Distrito Federal. Diário Oficial da República Federativa do Brasil.

Brasil. (2014). Presidência da República. Lei $\mathrm{n}^{\circ}$ 13.021, de 8 de agosto de 2014. Dispõe sobre o exercício das atividades farmacêuticas nas farmácias comunitárias. Brasília. Distrito Federal. Diário Oficial da República Federativa do Brasil.

Brasil. (2014). Ministério da Saúde. Secretaria de Ciência, Tecnologia e Insumos Estratégicos. Departamento de Assistência Farmacêutica e Insumos Estratégicos. Serviços farmacêuticos na atenção básica à saúde / Ministério da Saúde, Secretaria de Ciência, Tecnologia e Insumos Estratégicos. Departamento de Assistência Farmacêutica e Insumos Estratégicos. - Brasília: Ministério da Saúde, 2014. 108 p.: il. - (Cuidado Farmacêutico na atenção básica; caderno 1). ISBN 978-85-334-2196-7). 
Brasil. (2016). Conselho Federal de Farmácia. Programa de Suporte ao Cuidado Farmacêutico na Atenção à Saúde - PROFAR / Conselho Federal de Farmácia. - Brasília: Conselho Federal de Farmácia. 76 p.

Brasil. (2016). Conselho Nacional de Saúde. Resolução nº 510, de 07 de abril de 2016. Dispõe sobre as normas aplicáveis a pesquisas em Ciências Humanas e Sociais cujos procedimentos metodológicos envolvam a utilização de dados diretamente obtidos com os participantes ou de informações identificáveis ou que possam acarretar riscos maiores o que os existentes na vida cotidiana. Brasília. Distrito Federal.

Brasil. (2017). Ministério da Educação. Conselho Nacional de Educação Câmara de Educação Superior. Resolução ${ }^{\circ}$ 6, de 19 de outubro de 2017. Institui as Diretrizes Curriculares Nacionais do Curso de Graduação em Farmácia e dá outras providências. Brasília. Distrito Federal.

Brasil. (2017). Ministério da Educação. Conselho Nacional de Educação. Conselho Nacional de Saúde. Resolução no 546 CNE/CES, de 7 de abril de 2017. Institui diretrizes curriculares nacionais do curso de graduação em Farmácia. Diário Oficial da União, Brasília, DF, 16 jun. 2017. Seção 1, p. 36.

Brasil.(2009). Ministério da Saúde. Secretaria de Ciência, Tecnologia e Insumos Estratégicos, Departamento de Assistência Farmacêutica e Insumos Estratégicos. Diretrizes para estruturação de farmácias no âmbito do Sistema Único de Saúde. Brasília: Ministério da Saúde; 2009. 44p.

Choe, H. M., Lin, A. T., Kobernik, K., Cohen, M., Wesolowicz, L., Qureshi, N., Leyden, T., Share, D. A., Darland, R., \& Spahlinger, D. A. (2018). Michigan pharmacists transforming care and quality: Developing a statewide collaborative of physician organizations and pharmacists to improve quality of care and reduce costs. Journal of Managed Care \& Specialty Pharmacy. 24(4), 373-378. https://doi.org/10.18553/jmcp.2018.24.4.373

Cordina, M., Safta, V., Ciobanu, A., \& Sautenkova, N. (2008). An assessment of community pharmacists' attitudes towards professional practice in the Republic of Moldova. Pharmacy practice. 6(1):1-8. https://doi.org/10.4321/s1886-36552008000100001

Correr, C. J., Otuki, M. F., \& Soler, O. (2011). Assistência farmacêutica integrada ao processo de cuidado em saúde: gestão clínica do medicamento. Rev PanAmaz Saúde. 2(3):41-49.

Costa, F. A., Scullin, C., Al-Taani, G., Hawwa, A. F., Anderson, C., Bezverhni, Z., Binakaj, Z., Cordina, M., Foulon, V., Garcia de Bikuña, B., de Gier, H., Granås, A. G., Grinstova, O., Griese-Mammen, N., Grincevicius, J., Grinceviciene, S., Kaae, S., Kubiliene, L., Mariño, E. L., Westerlund, T. (2017). Provision of pharmaceutical care by community pharmacists across Europe: Is it developing and spreading? Journal of Evaluation in Clinical Practice, 23(6), 1336-1347. https://doi.org/10.1111/jep.12783

Cruz, W. M., Queiroz, L. M. D., Soler, O. (2020). Cuidado farmacêutico para utentes de farmácia comunitária privada: Revisão sistemática. Braz. J. of Develop. 6(10):78682-78702. ISSN 2525-8761. DOI:10.34117/bjdv6n10-340

Dos Reis, T. M., Guidoni, C. M., Girotto, E., Rascado, R.R., Mastroianni, P.C., Cruciol, J.M. \& Pereira, L. R. L. (2015). Assistência farmacêutica em farmácias comunitárias brasileiras: Conhecimento e prática. African Journal of Pharmacy and Pharmacology, 9 (9), 287-294. https://doi.org/10.5897/AJPP2014.4239

Dosea, A. S., Brito, G. C., Santos, L. M. C., Marques, T. C., Balisa-Rocha, B., Pimentel, D., Bueno, D., \& Lyra, D. P. (2016). Establishment, implementation, and consolidation of clinical pharmacy services in community pharmacies. Qualitative Health Research, 27(3), 363-373. https://doi.org/10.1177/1049732315614294

El Hajj, M. S., AL-Saeed, H. S., \& Khaja, M. (2016). Qatar pharmacists' understanding, attitudes, practice and perceived barriers related to providing pharmaceutical care. International Journal of Clinical Pharmacy, 38(2), 330-343. https://doi.org/10.1007/s11096-016-0246-0

Farina, S. S., \& Romano-Lieber, N. S. (2009). Atenção farmacêutica em farmácias e drogarias: Existe um processo de mudança? Saúde e Sociedade, 18(1), 718. https://doi.org/10.1590/s0104-12902009000100002

Ferreira, R. L. \& Soler, O. (2021). Prática de governança e gestão técnica da assistência farmacêutica no Município de Xinguara, Pará. Research, Society and Development, 10(4). http://dx.doi.org/10.33448/rsd-v10i4.14416

Gomes, C. A. P. G., Fonseca, A. L., Machado, M. C. Rosa, M. B., Fassy, M. F., Silva, R. M. C., Santos, F. J. P., \& Soler, O. (2010). A assistência farmacêutica na atenção à saúde. Belo Horizonte: Ed. FUNED. 144 p.

Holdford, D. A. (2018). Resource-based theory of competitive advantage - a framework for pharmacy practice innovation research. Pharmacy Practice, 16(3):1351. https://doi.org/10.18549/pharmpract.2018.03.1351

Melo, A. C., Trindade, G. M., Freitas, A. R., Resende, K. A., \& Palhano, T. J. (2021). Community pharmacies and pharmacists in Brazil: A missed opportunity. Pharm Pract (Granada). 19(2):2467. https://doi.org/10.18549/PharmPract.2021.2.2467

Melo, A. C., Trindade, G. M., Freitas, A. R., Resende, K. A., \& Palhano, T. J. (2021). Community pharmacies and pharmacists in Brazil: A missed opportunity. Pharmacy Practice. 19(2):2467. https://doi.org/10.18549/pharmpract.2021.2.2467

Mendes, E. V. (2012). O cuidado das condições crônicas na atenção primária à saúde: o imperativo da consolidação da estratégia da saúde da família. Brasília: Organização Pan-Americana da Saúde. 512 p.: il. ISBN: 978-85-7967-078-7

Minayo, M. C. S.; Costa, A. P. (2018). Fundamentos Teóricos das Técnicas de Investigação Qualitativa. Revista Lusófona de Educação, 40:139-153. ISSN 16457250

Moullin, J. C., Sabater-Hernández, D., \& Benrimoj, S. I. (2016). Qualitative study on the implementation of professional pharmacy services in Australian community pharmacies using framework analysis. BMC Health Services Research, 16(1). https://doi.org/10.1186/s12913-016-1689-7

Muller, M. (2019). Serviços Farmacêuticos - A Nova Aposta na Competição do Varejo. Instituto de Ciência, Tecnologia e Qualidade. https://ictq.com.br/varejofarmaceutico/775-servicos-farmaceuticos-a-novaaposta-na-competicao-do-varejo.

Oliveira, N. V. B. V. d., Szabo, I., Bastos, L. L., \& Paiva, S. P. (2017). Atuação profissional dos farmacêuticos no Brasil: Perfil sociodemográfico e dinâmica de trabalho em farmácias e drogarias privadas. Saúde e Sociedade. 26(4):1105-1121. https://doi.org/10.1590/s0104-12902017000002 
Research, Society and Development, v. 11, n. 2, e33611225743, 2022 (CC BY 4.0) | ISSN 2525-3409 | DOI: http://dx.doi.org/10.33448/rsd-v11i2.25743

Qato, D. M., Zenk, S., Wilder, J., Harrington, R., Gaskin, D., \& Alexander, G. C. (2017). The availability of pharmacies in the United States: 2007-2015. Plos One. 12(8):Artigo e0183172. https://doi.org/10.1371/journal.pone.0183172

Reis, T. M., Rocha, K. S. S., Barros, I. M. C., Santos, L. M. C., Paixão, F. P., Almeida, F. H. O., et al. (2015). Pharmacists' skills in conducting clinical services in community pharmacies in urban areas of Northeast Brazil. Latin American Journal of Pharmacy, 34(4), 725-731. 725-731 Lyra LAJP 4066: Lyra (latamjpharm.org)

Santos Júnior, G. A. d., Ramos, S. F., Pereira, A. M., Dosea, A. S., Araújo, E. M., Onozato, T., Pimentel, D. M. M., \& Lyra, D. P. d. (2018). Perceived barriers to the implementation of clinical pharmacy services in a metropolis in Northeast Brazil. Plos One, 13(10), Artigo e0206115 https://doi.org/10.1371/journal.pone.0206115

Serafin, C., Júnior D. C., Vargas M. (2015). Perfil do farmacêutico no Brasil: relatório. - Brasília: Conselho Federal de Farmácia. 44p.: il. ISBN 978-85-89924$16-0$

Soler, O., Rosa, M. B., Fonseca, A. L., Fassy, M. F., Machado, M. C., Silva, R. M. C., Gomes, C. A. P. (2010). Assistência farmacêutica clínica na atenção primária à saúde por meio do Programa Saúde da Família. Rev. Bras. Farm. 91(1):37-45. ISSN 0370-372X

Soler, O., Sinimbu, A. V., Figueredo, D. C. d., Vieira, H. K. d. S., Galucio, N. C. d. R., Pinheiro, P. D. N. Q., Sena, S. S. I., Silva, V. G. d., Vieira, V. M. B., \& Ledo, Y. (2018). A reorientação da assistência farmacêutica na secretaria municipal de saúde de Belém (PA): Relato de experiência. Revista Eletrônica de Farmácia, 14(4). https://doi.org/10.5216/ref.v14i4.45427

Turato, E. R. (2005). Métodos qualitativos e quantitativos na área da saúde: Definições, diferenças e seus objetos de pesquisa. Revista de Saúde Pública, 39(3), 507-514. https://doi.org/10.1590/s0034-89102005000300025

Yin, R. K. (2015). Estudo de caso: Planejamento e métodos. (5 ed.). Bookman.

Zekan, L., Mestrovic, A., Seselja Perisin, A., Portolan, M., Jambrek, N., Jager, S., Sepetavc, M., \& Modun, D. (2017). Clinical knowledge of community pharmacists in Croatia for detecting drug-related problems. International journal of clinical pharmacy, 39(6), 1171-1174. https://doi.org/10.1007/s11096-0170546-Z 